\title{
THERMAL EFFECT ON THE CREEP IN A ROTATING DISC BY USING SHERBY'S LAW
}

\author{
Pankaj Thakur ${ }^{1 *}$, Nishi Gupta², Satya Bir Singh ${ }^{2}$ \\ ${ }^{1}$ Department of Mathematics, ICFAI University Baddi, Solan, Himachal Pradesh 174103, India \\ ${ }^{2}$ Department of Mathematics, Punjabi University Patiala, Punjab 147002, India \\ *Corresponding author; E-mail: dr_pankajthakur@yahoo.com
}

(Received April 6, 2016; Accepted July 5, 2016))

\begin{abstract}
The effect of imposing linear thermal gradient on the steady state creep behavior of a rotating functionally graded $\mathrm{Al}-\mathrm{SiCp}$ disc is investigated in the present study by using Sherby's law. Mathematical model to describe steady state creep behavior in rotating disc made of isotropic $\mathrm{Al}-\mathrm{SiC}$ composite in presence of linear thermal gradient in the radial direction has been formulated. The distributions of stresses and strain rates have been obtained. The creep response of a composite disc with uniform temperature has also been computed for comparison with the results obtained for thermally graded discs. The creep rates in a rotating thermally graded disc can be significantly reduced in presence of thermal gradients.
\end{abstract}

Keywords Creep, disc, functionally graded material, thermal, composites.

\section{INTRODUCTION}

Rotating discs have many practical engineering applications such as in steam and gas turbine rotors, high speed gear engine, turbo generators, internal combustion engines, turbojet engines, reciprocating and centrifugal compressors just to mention a few. In these applications, the performance of the component in terms of efficiency, service life and power transmission certainly depends on the material, speed of rotation and operating conditions. Normally, a component can be fabricated using any metal. However, for some specific applications such as in aerospace engineering where the component's weight and durability in high temperature environment are so crucial, the components need to be fabricated using special material such as a functionally graded material. FGMs are usually made of a mixture of ceramic and metals. The ceramic constituent of the material provides the high temperature resistance due to its low thermal conductivity. The ductile metal constituent, on the other hand, prevents fracture caused by stress due to high temperature gradient in a very short period of time.

WAHL et al. (1954) conducted the creep test in a rotating disc made of steel and simulated these results theoretically using von Mises and Tresca Yield criteria. The creep behavior of the disc material was described by power law relation. MA (1959) used maximum shear stress theory to analyze steady state creep in a metallic gas turbine rotating solid disc of variable thickness operating at a constant elevated temperature. BHATNAGAR et al (1966, $1974,1980)$ studied the stress and strain rate distribution in the wall of a hollow thick walled 
rotating cylinder using Norton's law for steady state creep and observed that the stress and strain rate distributions are significantly affected by the anisotropy of the material and value of exponent $n$. PANDEY et al. (1992) studied the affect of volume fraction and size of reinforcement on the steady state creep behavior of Al-SiCp composites for temperature 623$723 \mathrm{k}$ and observed that apparent stress exponents are more than 15 and apparent activation energy is $294 \mathrm{~kJ} / \mathrm{mol}$. They observed the effective stress-strain rate behavior of composite agreed with the stress dependent sub-structure invariant model.

SINGH et al. (1998) performed creep analysis in an anisotropic $6061 \mathrm{Al}^{-S i C_{\mathrm{w}}}$ disc rotating at $15,000 \mathrm{rpm}$ and undergoing steady state creep described by power law at $561 \mathrm{~K}$. DuRODOLA et al. (2000) investigated the potential benefits of using several forms of the fiber gradation in FGM rotating disc using finite element method and direct numerical integration. It was observed that the different forms of property gradation modify the stress and displacement fields in FGM discs compared with uniformly reinforced discs. SINGH and RAY (2001) estimated steady state creep response using Norton's power law in an isotropic FGM rotating disc of aluminum-silicon carbide particulate composites at uniform elevated temperature. They concluded that the steady state creep response of the FGM disc is significantly superior compared to a disc with the same total particle content distributed uniformly. SINGH and RAY (2003) proposed a new yield anisotropic criterion for residual stress, which at appropriate limits reduces to Hill anisotropic and Hoffman isotropic yield criteria and carried out analysis of steady state creep in a rotating disc made of $\mathrm{Al}-\mathrm{SiCw}$ composite using these criteria and compared the results obtained using Hill anisotropic yield criteria ignoring difference in yield stresses. SINGH and RAY (2004) studied the effect of thermal residual stress on the steady state creep behavior of a rotating disc made of $6061 \mathrm{Al}-$ $20 \mathrm{vol} \% \mathrm{SiC}_{\mathrm{w}}$ composite using isotropic Hoffman yield criterion while describing the creep by Norton's power law. The authors concluded that the tensile residual stress significantly affects the strain rates in the disc when compared with the strain rate in the disc without residual stress.

ALEXANDROVA and ALEXANDROV (2004) investigated stresses and strains in an elastic-perfectly plastic isotropic rotating annular disc of constant thickness and density using Mises yield criterion and associated flow rule. You et al. (2007) presented a simple method based on basic equations of axisymmetric, plain strain and steady state creep to determine stresses and creep strain rates in thick walled cylindrical vessels made of functionally graded materials subjected to internal pressure. BAYAT et al. (2008) obtained elastic solutions for symmetric rotating discs made of functionally graded materials with variable thickness. SINGH (2008) have performed creep analysis in an anisotropic 6061 $\mathrm{Al} 20 \mathrm{vol} \% \mathrm{SiC}_{\mathrm{w}}$ composite disc rotating at $15,000 \mathrm{rpm}$ and undergoing steady state creep at $561 \mathrm{~K}$ following Norton's power law. SHARMA and SAHNI (2008) obtained creep transition of transversely isotropic thick-walled rotating cylinder.

CHEN et al. (2009) investigated the coefficient of thermal expansion (CTE) and accumulated plastic strain of the pure aluminum matrix composite containing $50 \% \mathrm{SiC}$ particles $\left(\mathrm{Al} / \mathrm{SiC}_{\mathrm{p}}\right)$ during thermal cycling within temperature range $298-573 \mathrm{~K}$. The discs under investigation are made of composite containing silicon carbide particles in a matrix of pure aluminum. The creep behavior of the composite has been described by threshold stress based creep law by assuming a stress exponent of 5. A mathematical model has been developed to investigate steady state creep in a rotating disc of functionally graded composite having linearly varying thickness. CHAMOLI et al. (2010) studied steady state creep behavior of an anisotropic rotating disc. The stress and strain rate distribution is calculated for anisotropic disc and concluded that the anisotropy of the material has a significant effect on the creep of a rotating disc. RATTAN et al. (2010) has investigated the stress distributions and the resulting creep deformation in isotropic rotating disc having constant thickness made of silicon carbide particulate reinforced with aluminum base composite in presence of thermal 
residual stress. It is concluded that the presence of the tensile residual stress affects the distribution of stresses and strain in the disc with constant thickness. CALLIOGLU et al. (2011) studied that stress analysis on functionally graded rotating annular discs subjected to temperature distributions parabolically decreasing with radius. The authors concluded that with the increasing temperature, the tangential stress component decreased at the inner surface whereas increased at the outer surface and the radial stress component reduced gradually for all the temperature distributions.

GUPTA et al. (2007) analyzed thermo elastic-plastic Transition in a thin rotating disc with Inclusion by using Set's transition theory. THAKUR et al. (2013, 2014, 2015, 2016a,b) studied the problem of rotating disc with variable thickness, thermal effect, heat generation effect and pressure by using Seth's transition theory. GUPTA et al. (2016) discuss variation of Poisson ratios and thermal creep stresses and strain rates in an isotropic Disc. KAUR et al. (2016) study steady thermal stresses in a thin rotating disc of finitesimal deformation with edge loading.

In the present study, the influence of thermal gradient on the steady state creep response of a rotating disc has been studied for three different cases. In the first case, the disc is assumed to operate under uniform temperature of $625 \mathrm{~K}$ while in the second case, the disc is assumed to operate under thermal gradient of $52 \mathrm{~K}$ by taking temperature at inner and outer radii as $658 \mathrm{~K}$ and $588 \mathrm{~K}$ respectively. In the third case, the disc is assumed to operate under thermal gradient of $110 \mathrm{~K}$ by taking temperature at inner and outer radii as $623 \mathrm{~K}$ and $563 \mathrm{~K}$ respectively. The average temperature in all the cases is kept at $633 \mathrm{~K}$ to justify the comparison. The inner and outer radii of the disc are taken as $32.35 \mathrm{~mm}$ and $154.4 \mathrm{~mm}$ respectively and the thickness of disc is assumed to be $26.4 \mathrm{~mm}$.

In this paper, the disc is assumed to operate under linear thermal gradient, as given by

$$
T(r)=A-B r, a \leq r \leq b
$$

where

$$
A=\frac{b T_{\max }-a T_{\min }}{b-a}
$$

and

$$
B=\frac{T_{\max }-T_{\min }}{b-a}
$$

Here $T_{\max }$ and $T_{\min }$ are, respectively, the temperatures at the inner and outer radii.

\section{ESTIMATION OF CREEP PARAMETERS}

The steady-state creep response of the $\mathrm{Al}-\mathrm{SiC}_{\mathrm{p}}$ composite of varying composition is described in terms of Sherby threshold stress based model given by

where,

$$
\dot{\bar{\varepsilon}}=\left[M(r)\left(\bar{\sigma}-\sigma_{0}(r)\right)\right]^{8}
$$

$$
M=\frac{1}{E}\left[\frac{A D_{L} \lambda^{3}}{\left|\vec{b}_{r}\right|^{5}}\right]^{1 / 8}
$$


and $\bar{\sigma}$ is effective stress, $\dot{\bar{\varepsilon}}$ is effective strain rate, $M$ is material creep constant, $D_{L}$ is the lattice diffusivity, $\lambda$ is the sub grain size, $\mathrm{A}$ is the constant, $\left|\vec{b}_{r}\right|$ is the magnitude of Burger's vector, $E$ is the young's modulus and $\sigma_{0}$ is the threshold stress.

The values of creep parameters $M$ and $\sigma_{0}$ have been obtained from the creep results reported for $\mathrm{Al}-\mathrm{SiC}_{\mathrm{p}}$ composite (PANDEY et al., 1992) and these values have been fitted by the following regression equations as a function of particle size $(P)$, temperature $(T)$ and volume percent $(V)$.

$$
\begin{aligned}
& \ln M(r)=-34.91+0.2112 \ln P+4.89 \ln T(r)-0.591 \ln V \\
& \sigma_{0}(r)=-0.02050 P+0.01378 T(r)+1.033 V-4.9695
\end{aligned}
$$

The variation of creep parameters in the rotating thermally graded discs along the radial distance has been determined in this study from the preceding equations for $P=1.7 \mu \mathrm{m}$ and $V=10 \mathrm{vol} \%$.

\section{MATHEMATICAL FORMULATION}

Consider an aluminum silicon-carbide particulate composite disc of constant thickness $\mathrm{h}$ having inner radius, $a$, and outer radius, $b$, rotating with angular velocity, $\omega(\mathrm{radian} / \mathrm{sec})$. From symmetry considerations, principal stresses are in the radial, tangential and axial directions. The following assumptions are made for the purpose of analysis.

1. Steady state condition of stress is assumed.

2. Elastic deformations being relatively small for the disc and may be neglected as compared to the creep deformation.

3. The thickness is small as compared to its diameter therefore axial stress is assumed to be zero on the faces of the disc.

For biaxial state of stress, the generalized constitutive equations for creep in an isotropic composite take the following form when reference frame is taken along the principal directions $r, \theta$ and $z$ :

$$
\begin{aligned}
& \dot{\varepsilon}_{r}=\frac{\dot{\bar{\varepsilon}}}{2 \bar{\sigma}}\left[2 \sigma_{r}-\sigma_{\theta}\right] \\
& \dot{\varepsilon}_{\theta}=\frac{\dot{\bar{\varepsilon}}}{2 \bar{\sigma}}\left[2 \sigma_{\theta}-\sigma_{r}\right] \\
& \dot{\varepsilon}_{z}=\frac{\dot{\bar{\varepsilon}}}{2 \bar{\sigma}}\left[-\left(\sigma_{r}+\sigma_{\theta}\right)\right]
\end{aligned}
$$

where $\dot{\varepsilon}_{r}, \dot{\varepsilon}_{\theta}, \dot{\varepsilon}_{z}$ and $\sigma_{r}, \sigma_{\theta}, \sigma_{z}$ are strain rates and stresses respectively in the directions $r, \theta$ and $z$ as indicated by the subscripts.

Assuming that the effective stress is based on Mises criterion (1913), for biaxial state of stress, effective stress, $\bar{\sigma}$ is given as,

$$
\bar{\sigma}=\frac{1}{\sqrt{2}}\left[\sigma_{r}^{2}+\sigma_{\theta}^{2}+\left(\sigma_{r}-\sigma_{\theta}\right)^{2}\right]^{1 / 2}
$$


Using eqs. (4) and (8) in constituting eqs. (7), one gets,

$$
\begin{aligned}
& \dot{\varepsilon}_{r}=\frac{d \dot{u}_{r}}{d r}=\frac{\left[M(r)\left(\bar{\sigma}-\sigma_{0}(r)\right)\right]^{8}(2 x(r)-1)}{2\left[(x(r))^{2}-x(r)+1\right]^{1 / 2}} \\
& \dot{\varepsilon}_{\theta}=\frac{\dot{u}_{r}}{r}=\frac{\left[M(r)\left(\bar{\sigma}-\sigma_{0}(r)\right)\right]^{8}(2-x(r))}{2\left[(x(r))^{2}-x(r)+1\right]^{1 / 2}} \\
& \dot{\varepsilon}_{z}=\frac{-\left[M(r)\left(\bar{\sigma}-\sigma_{0}(r)\right)\right]^{8}(x(r)+1)}{2\left[(x(r))^{2}-x(r)+1\right]^{1 / 2}}
\end{aligned}
$$

where $x(r)=\sigma_{r}(r) / \sigma_{\theta}(r)$ is the ratio of radial and tangential stress at any radius $r$. Equations (9) and (10) can be solved to obtain $\sigma_{\theta}(r)$ as given

$$
\sigma_{\theta}(r)=\frac{\left(\dot{u}_{a}\right)^{1 / 8}}{M(r)} \psi_{1}(r)+\psi_{2}(r)
$$

where

$$
\begin{aligned}
& \dot{u}_{a}^{1 / 8}=\frac{\int_{a}^{b} M(r) \sigma_{\theta} d r-\int_{a}^{b} M(r) \psi_{2}(r) d r}{\int_{a}^{b} \psi_{1}(r) d r}, \\
& \psi_{1}(r)=\frac{\psi(r)}{\left[(x(r))^{2}-x(r)+1\right]^{1 / 2}}, \\
& \psi_{2}(r)=\frac{\sigma_{0}(r)}{\left[(x(r))^{2}-x(r)+1\right]^{1 / 2}}, \\
& \psi(r)=\left[\frac{2\left[(x(r))^{2}-x(r)+1\right]^{1 / 2}}{r(2-x(r))} \exp \int_{a}^{r} \frac{\phi(r)}{r} d r\right]^{\frac{1}{8}},
\end{aligned}
$$

and

$$
\phi(r)=\frac{(2 x(r)-1)}{(2-x(r))} .
$$

The equation of motion of the rotating disc with constant thickness $h$ may be obtained by considering the equilibrium of an element in the composite disc confined between radial distance $r$ and $r+d r$ and an interval of angle between $\theta$ and $\theta+d \theta$. The equilibrium of forces in the radial direction are

$$
\frac{d}{d r}\left[r \sigma_{r}(r)\right]-\sigma_{\theta}(r)+\rho \omega^{2} r^{2}=0
$$

Integrating eqn. (18) from $a$ to $b$ and putting the boundary conditions $\sigma_{r}=0$ at $r=a$ and $\sigma_{r}=0$ at $r=b$ one gets, 


$$
\int_{a}^{b} \sigma_{\theta} d r=\rho \omega^{2}\left(b^{3}-a^{3}\right) / 3
$$

In the first iteration, $\sigma_{\theta}=\sigma_{\theta_{\text {avg }}}$, where $\sigma_{\theta_{\text {avg }}}$ is the average tangential stress over the cross section of the disc. Therefore eqn. (13) in the first iteration may be written as,

$$
\dot{u}_{a}^{1 / 8}=\frac{\sigma_{\theta_{a v g}} \int_{a}^{b} M(r) d r-\int_{a}^{b} M(r) \psi_{2}(r) d r}{\int_{a}^{b} \psi_{1}(r) d r}
$$

The values of $\sigma_{r}(r)$ can be as obtained by integrating eqn. (18) from $a$ to $r$ as follows:

$$
\sigma_{r}(r)=\frac{1}{r} \int_{a}^{r} \sigma_{\theta}(r) d r-\frac{\rho \omega^{2}\left(r^{3}-a^{3}\right)}{3 r}
$$

Knowing the values of $\sigma_{\theta}(r)$ from eqn. (12), the radial stress, $\sigma_{r}$ is determined by eqn. (21) at any point within the composite disc and the strain rates $\dot{\varepsilon}_{r}$ and $\dot{\varepsilon}_{\theta}$ are calculated from equations (9) and (10) respectively.

\section{NUMERICAL COMPUTATIONS}

The stress distribution is evaluated from the above analysis by iterative numerical scheme of computation.

$$
\sigma_{\theta} \rightarrow \sigma_{\theta_{\text {avg }}} \rightarrow\left(\sigma_{r}\right)_{1} \rightarrow(x)_{1} \rightarrow \phi(r)_{1} \rightarrow \psi(r)_{1} \rightarrow\left(\sigma_{\theta}\right)_{1}
$$

The iteration is continued till the process converges yielding the values of stresses at different points of the radius grid. For rapid convergence, the following relation has been used for next iteration;

$$
\sigma_{\theta_{\text {Next }}}=0.25 \sigma_{\theta_{\text {Previous }}}+0.75 \sigma_{\theta_{\text {Current }}}
$$

\section{RESULTS AND DISCUSSIONS}

A computer program based on the mathematical formulation has been developed to obtain the steady state creep response of the rotating isotropic disc with constant thickness. The ratios of isotropic constants of a composite disc has been taken as $\mathrm{G} / \mathrm{F}=2, \mathrm{H} / \mathrm{F}=2$. For all the discs, the inner radii $32.35 \mathrm{~mm}$ and the outer radii $154.4 \mathrm{~mm}$ respectively. The stress exponent and density of disc material have been taken as $\mathrm{n}=7$ and $\rho=2812.4 \mathrm{~kg} / \mathrm{m}^{3}$ respectively. To obtain the plastic stresses and strain rates, the results for a rotating steel disc using current analysis were obtained for the disc and operating conditions as mentioned in WAHL et al. (1954).

In Figure 1, the radial stress developing due to rotation in the isotropic disc operating under a thermal gradient is higher over the entire radius as compared to the isotropic disc without thermal gradients. In Figure 2, the tangential stresses in an isotropic rotating disc in presence of thermal gradients have been determined and the results are compared with those 
without thermal gradients. It has been observed that in the isotropic discs, the tangential stresses are little higher in region near the internal radius and slightly lower in region near the external radius in the presence of thermal gradient as compared to the disc without temperature gradient. Although, the variation in the magnitude of tangential as well as radial stress distribution is small in the isotropic disc due to presence of temperature gradients. Figure 3 shows the effect of imposing temperature on radial strain rate in the isotropic disc. It is clear that the trend of variation of radial strain rate is similar in all the discs where as the magnitude of radial strain rate firstly increases rapidly with radial distance and then starts to be decreasing. It reaches a minimum before increasing again towards the external radius in the isotropic disc in the presence/absence of temperature gradients. Figure 4 shows the variation of tangential strain rate along radius in presence/absence of temperature gradients. It is clear that the tangential strain rate decreases significantly over the entire radius in the isotropic disc operating under the thermal gradients as compared to the disc without thermal gradients. As such the temperature over the entire radius of the disc with temperature gradients dominates the creep behaviour as compared to those observed in the disc under isothermal condition.

It has also been observed that the strain rates decrease significantly over the entire radius in the isotropic disc operating under the temperature gradients and it may lead to reducing the extent of distortion in the disc. This analysis may be useful whenever one is interested in safe design of a rotating disc under elevated temperatures.

\section{D Graph 1}

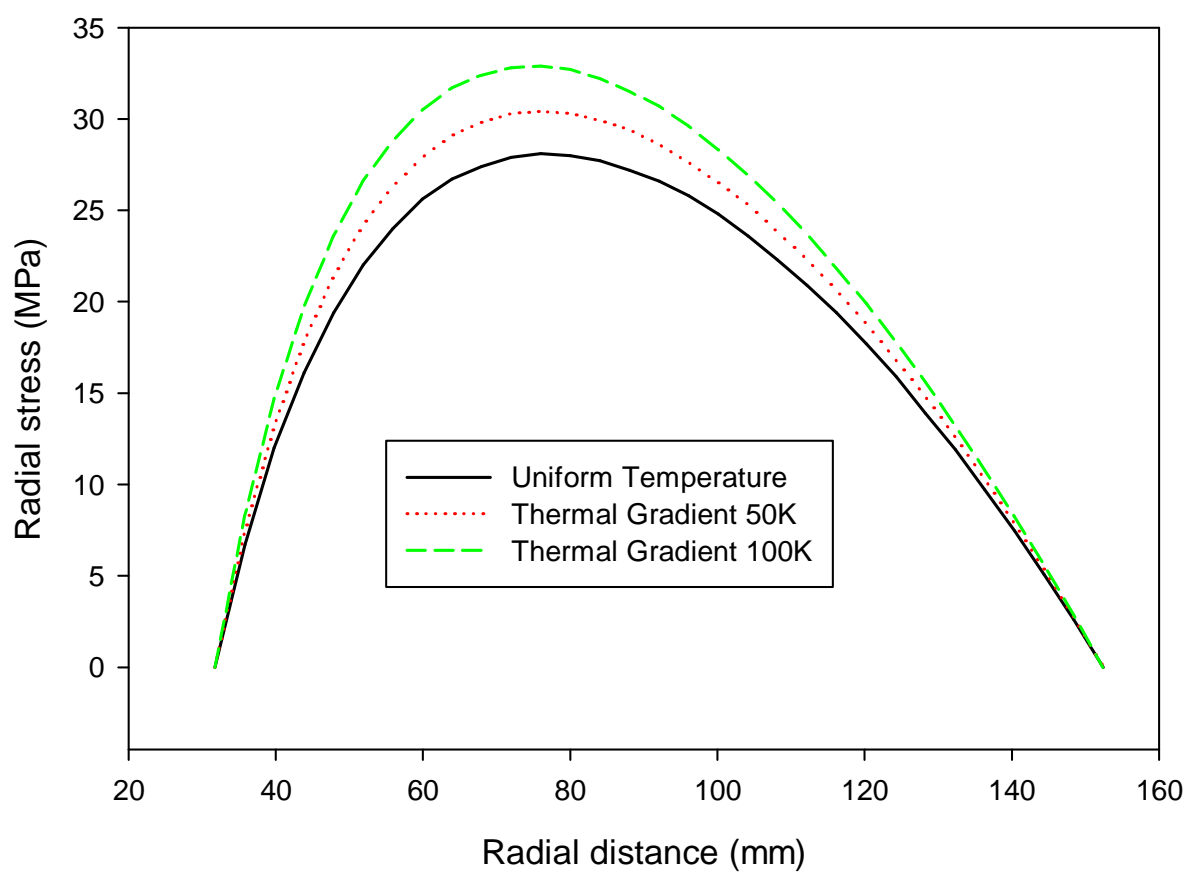

Figure 1. Variation of radial stress along the radial distance with composite disc with/without thermal gradient. 
2D Graph 2

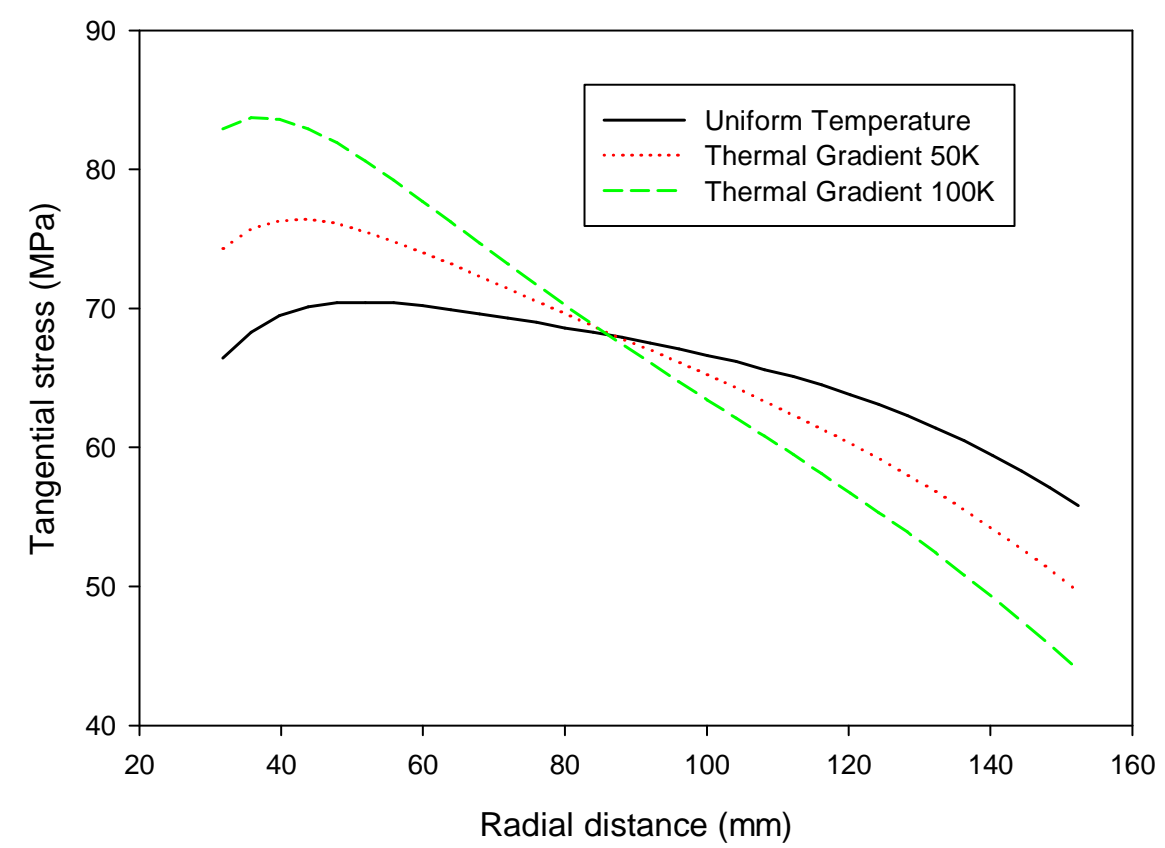

Figure 2. Variation of tangential stress along the radial distance with composite disc with/without thermal gradient.

\section{D Graph 3}

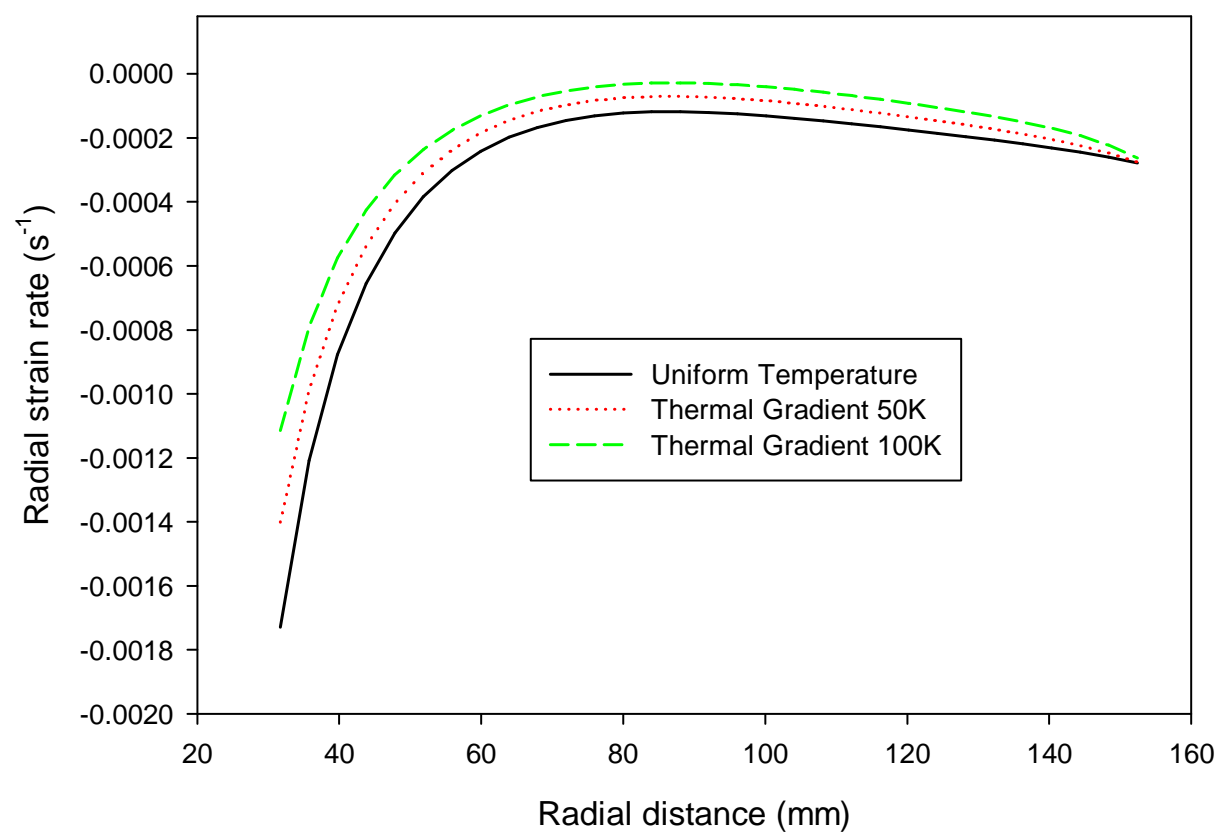

Figure 3. Variation of radial strain rate along the radial distance with composite disc with/without thermal gradient. 


\section{D Graph 4}

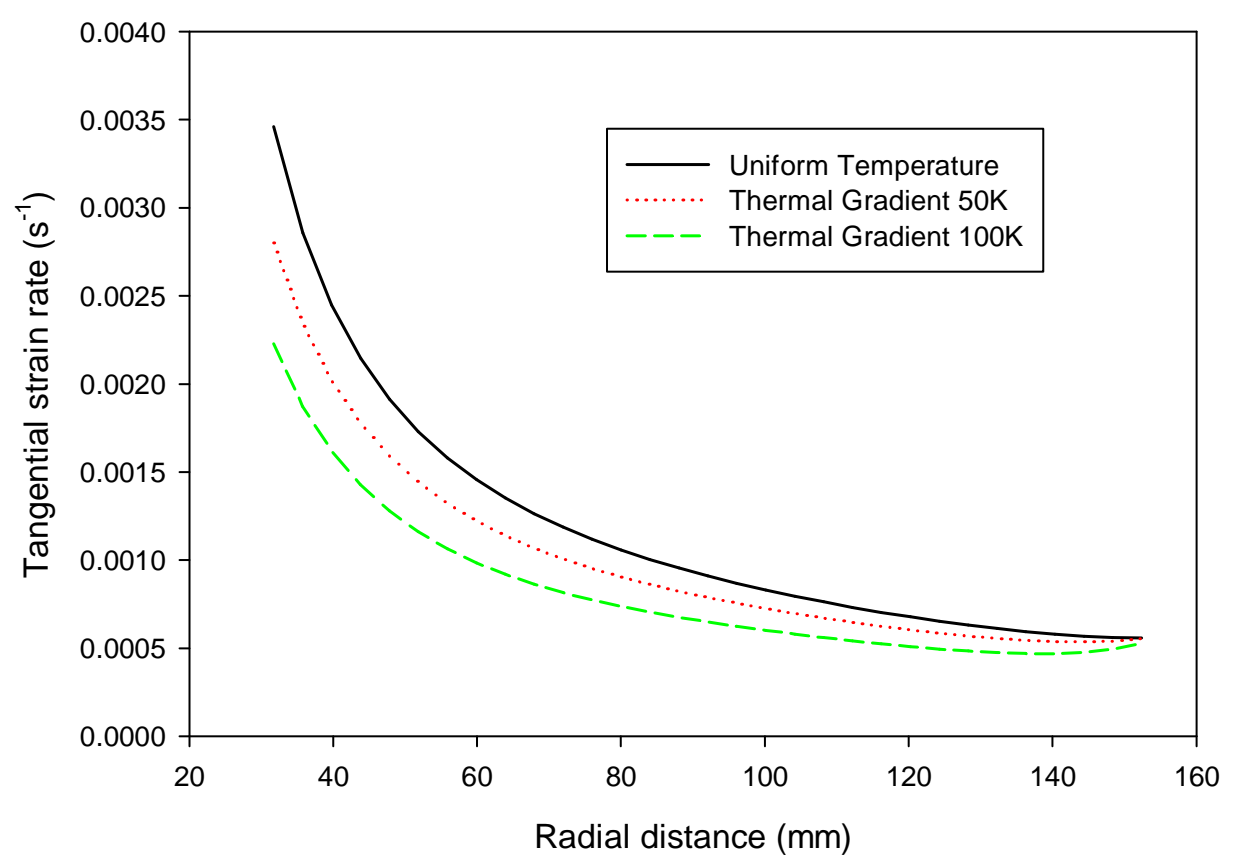

Figure 4. Variation of tangential strain rate along the radial distance wiyh composite disc with/without thermal gradient.

\section{References:}

[1] Alexandrova, N., AleXandrov, S. (2004): Elastic-Plastic Stress Distribution in a Rotating Annular Disc. Mechanics Based Design of Structures and Machines 32 (1): 115.

[2] Bayat, M., Saleem, M., SAhari, B.B, Madhi E.: (2008): Analysis of Functionally Graded Rotating Disks with Variable Thickness. Mechanics Research Communications 35: 283-309.

[3] Bhatnagar, N.S., Arya, V.K. (1966): On the Constitutive Equations of the Orthotropic Theory of Creep. Journal of Physical Society of Japan 4: 1003-1007.

[4] Bhatnagar, N.S., Arya, V.K. (1974): Large Strain Creep Analysis of Thick-Walled Cylinder. International Journal of Non-linear Mechanics 4: 127-140.

[5] Bhatnagar, N.S., Arya, V.K., Debnath, K.K. (1980): Creep Analysis of Orthotropic Rotating Cylinder. Journal of Pressure Vessels Technology 102: 371-377.

[6] Chen, N., Zhang, H., Gu, M., Jin, Y. (2009): Effect of Thermal Cycling on the Expansion Behavior of Al-SiCp composite. Journal of Materials Processing Technology 209 (3): 1471-1476.

[7] Chamoli, N., RatTan, M. Singh, S.B. (2010): Effect of Anisotropy on the Creep of a Rotating Disc of Al-SiCp Composite. Int. J. Contemp. Math. Sciences 5 (11): 509-516. 
[8] Callioglu, H., Demir, E., SAYer, M. (2011): Thermal Stress Analysis of Functionally Graded Rotating Discs. Scientific Research and Essays 6 (6): 3437 -3446

[9] Durodola, J.F., Attia, O. (2000): Deformation and Stresses in Functionally Graded Rotating Disks. Composites Science and Technology 60 (7): 987-995.

[10] GuPTA, S.K., PANKaJ, T. (2007): Thermo Elastic-Plastic Transition in a Thin Rotating Disc with Inclusion. Thermal Science 11 (1): 103-118.

[11] Gupta, N., Singh, S.B., ThaKur, P. (2016): Determine variation of Poisson ratios and thermal creep stresses and strain rates in an isotropic Disc, Kragujevac Journal of Science 38: 15-28.

[12] Kaur, J., Thakur, P., Singh, S.B. (2016): Steady thermal stresses in a thin rotating disc of finitesimal deformation with edge loading, Journal of Solid Mechanics, 8 (1): 204211.

[13] MA, B.M. (1959): A Creep Analysis of Rotating Solid Discs. Journal of the Franklin Institute 267: 167-168.

[14] Pandey, A.B., Misra, R.S., Mahajan, Y.R. (1992): Steady State Creep Behavior of Silicon), Carbide Particulate Reinforced Aluminum Composites. Acta Metallurgical Material 40 (8): 2045-2052.

[15] Rattan, M., Chamoli, N., Singh, S.B. (2010): Creep Analysis of an Isotropic Functionally Graded Rotating Disc. Int. J. Contemp. Math. Sciences 5 (9): 419-431.

[16] Sharma, S., SAHni, M. (2008): Creep Transition of Transversely Isotropic ThickWalled Rotating Cylinder. Adv. Theory. Appl. Mech. 78: 285-291.

[17] Singh, S.B., GuPTA, R.K., Bhatnagar, N.S., RAY, S. (1998): Influence of Anisotropy on Creep in a Whisker Reinforced MMC Rotating Disc. Proc.COMPEAT-98, National Metallurgical Laboratory, Jamshedpur, India: 83-102.

[18] Singh, S.B., RAY, S. (2001): Steady-State Creep Behavior in an Isotropic Functionally Graded Material Rotating Disc of Al-SiC Composite. Metallurgical Transactions 32A: 1679-1685.

[19] Singh, S. B., RAY, S. (2003): Newly Proposed Yield Criterion for Residual Stress and Steady State Creep in an Anisotropic Composite Rotating Disc. Journal of Materials Proceeding and Technology 143-144: 623-628.

[20] Singh, S.B., RAY, S. (2004): Modeling the Creep in an Isotropic Rotating Disc of Al$\mathrm{SiCw}$ composite in presence of thermal residual stress. Proc. 3rd International Conference on Advanced Manufacturing Technology: ICAMT-2004, May 11-13, Kuala Lumpur, Malaysia: 766-770.

[21] SingH, S.B. (2008): One Parameter Model for Creep in a Whisker Reinforced Anisotropic Rotating Disc of AI-SiCw Composite. European Journal of Mechanics A/Solids 27 (4): 680-690.

[22] Thakur, P., KAUR, J., Singh, S.B. (2013): Thickness variation parameter in thin rotating disc. FME Transaction, 41 (2): 96-102.

[23] Thakur, P., Kaur, J., Singh, S.B. (2014): Elastic-plastic transitional stress in a thin rotating disc with shaft having variable thickness under steady state temperature. Kragujevac Journal of Science 36: 5-17. 
[24] Thakur, P., Singh, S.B., Lozanović ŠAJIĆ, J. (2015): Thermo elastic-plastic deformation in a solid disk with heat generation subjected to pressure. Structural Integrity and Life 15 (3): 135-142.

[25] Thakur, P., Singh S.B., Singh, J., Kumar, S. (2016a): Steady Thermal Stresses in Solid Disk under heat generation subjected to variable Density, Kragujevac Journal of Science, 38: 5-14.

[26] Thakur, Pankaj, Kaur Jatinder, Singh S.B. (2016b): Thermal creep transition stresses and strain rates in a circular Disc with shaft having variable density. Engineering Computations, Emerald Publisher UK 33 (3): 698-712.

[27] Wahl, A.M., SAnkey, G.O., Manjoine, M.J., Shoemaker, E. (1954): Creep Tests of Rotating Disks at Elevated Temperature and Comparison with Theory. Journal of Applied Mechanics 76: 225-235.

[28] You, L.H. et al. (2007): Creep Deformations and Stresses in Thick-Walled Cylindrical Vessels of Functionally Graded Materials Subjected to Internal Pressure. Composite Structures 78: 285-291. 